\title{
Quality of life profile and correlated factors in chronic leg ulcer patients in the mid-west of São Paulo State, Brazil
}

\author{
Patrick Alexander Wachholz ${ }^{1}$ \\ Cecilia Midori Higashi Taira ${ }^{4}$
}

\author{
Paula Yoshiko Masuda ${ }^{2}$ \\ Norma Gondim Cleto ${ }^{5}$
}

Dejair Caitano Nascimento ${ }^{3}$

\section{DOI: http://dx.doi.org/10.1590/abd1806-4841.20142156}

\begin{abstract}
BACKGROUND: Chronic leg ulcer may have an impact on patients' quality of life. OBJECTIVES: This study aimed to identify the impact of leg ulcers on patient's quality of life using the Dermatology Life Quality Index and to define the main factors correlated with this perception. METHOD: Cross-sectional, non-probabilistic sampling study. We included patients with chronic leg ulcers being treated for at least 3 months. A sociodemographic and clinical survey was conducted to assess the profile of the ulcers. We administered a screening for depressive symptoms and the Dermatology Life Quality Index. We performed a descriptive statistical analysis, chi-square test and Mann-Whitney test for categorical data, Pearson for numeric variables, and multiple regression for categorical data. RESULTS: Forty-one patients were assessed. Their mean age was 61.78 years. Venous ulcers (48.8\%) were the most prevalent. Seventy-three percent of the sample perceived no impact/low impact on quality of life in the past week, and $26.8 \%$ perceived moderate/high impact. A multiple regression analysis identified the causes of lesion, pain related to the ulcers, time of onset, and severity of the depressive symptoms as the variables that had an influence on quality of life. Conclusions: The majority of the sample perceived low or no impact of the condition on the quality of the life. The variables etiology of the lesion $(p<0.001)$, pain related to the ulcers $(p=0.001)$, time of onset $(p=0.006)$, and severity of the depressive symptoms $(p<0.001)$ had an influence on the quality of life, suggesting the need for further studies with more robust designs to confirm the causal relationship between these characteristics and quality of life.
\end{abstract}

Keywords: Leg ulcer; Quality of life; Varicose ulcer

\section{INTRODUCTION}

Chronic leg ulcers are skin lesions resulting from circumscribed or irregular loss of skin occurring below the knee, which take more than six weeks to heal. ${ }^{1}$

Population surveys estimate that chronic leg ulcers affect about 0.45 to $3.33 \%$ of the world population. Highest frequency is found among older adults and patients with vascular and metabolic diseases. ${ }^{2-6}$

The quality of life of patients with chronic leg ulcers can be impaired by a complex set of aspects, including physical symptoms caused by the ulcers, complications of the underlying disease or treatment, changes in functional capacity and mobility, social and employment limitations, as well as social and economic impacts. ${ }^{1}$
Recently, knowledge advanced to a wider understanding of the concept of quality of life (QoL). Furthermore, its use in clinical and research practice has allowed a more humanized therapeutic approach, closer to patients' needs, because it makes easier to define which treatments and interventions are more beneficial or harmful.?

Nevertheless, QoL assessment has become a variable of interest to health care providers because of its consistent association with relevant and unambiguous health aspects, such as mortality, hospitalization, and use of financial resources. ${ }^{8}$

Several studies have addressed the QoL in Brazil. ${ }^{7,-12}$ A recent review addressed the specific tools responsible for measuring the impact of skin diseases

\footnotetext{
Received on 24.09.2012.

Approved by the Advisory Board and accepted for publication on 23.02.2013.

Study conducted at Instituto Lauro de Souza Lima (ILSL) - Bauru (SP), Brazil.

Financial Support: None

Conflict of Interest: None

MD, Geriatrician and Internal Medicine - Master's Degree Student, Public Health Program, Botucatu Medical School - Universidade Estadual Paulista Júlio de Mesquita Filho (UNESP) - Bauru (SP), Brazil

MD, Preceptor, Medical Residency Program in Dermatology, Instituto Lauro de Souza Lima (ILSL) - Bauru (SP), Brazil.

Pharmacist, PhD in Pharmacology, Universidade de São Paulo (USP) - Scientific Researcher, Instituto Lauro de Souza Lima, Bauru - SP - Bauru (SP), Brazil.

Nurse - Technical Coordinator, Outpatient Clinic of Wounds, Instituto Lauro de Souza Lima (ILSL) - Bauru (SP), Brazil.

MD, Master's Degree in Medical Biotechnology, Universidade Estadual Paulista Julio de Mesquita Filho (Unesp) - Preceptor, Medical Residency Program in Dermatology, Instituto Lauro de Souza Lima (ILSL) - Bauru (SP), Brazil. 
on the QoL (such as the Dermatology Quality of Life Index - DLQI), and their impact in the choice of therapeutic options and eligibility and response criteria. ${ }^{13,14}$

A systematic review conducted by Herber et al. to evaluate the impact of leg ulcers on the QoL suggested that patients with chronic leg ulcers have significantly higher levels of pain, functional and social limitations, lower vitality, and emotional limitations when compared with controls. ${ }^{15}$ In spite of including a wide repertoire of variables and comparing different study designs in the same analysis, this review did not consider clinical factors related to specific characteristics of the lesions, as well as the impact of depressive symptoms on the perceived impact on the QoL related to the disease.

The objective of the present study was to determine the impact of chronic leg ulcers on the QoL using the DLQI, and to describe the main factors correlated with this perception.

\section{MATERIAL AND METHODS}

We conducted an analytical and descriptive cross-sectional study. The participants had chronic leg ulcers and were being treated at an outpatient clinic of dermatology in the city of Bauru, São Paulo, Brazil.

The present study complied with the international guidelines for research involving human subjects. It was approved by the Research Ethics Committee of the institution (Protocol no. 234/12).

A non-probabilistic sampling method was used. The sample selection was performed between February and May 2012. The inclusion criteria were: (a) to have chronic leg ulcer, ${ }^{1}$ regardless of the etiology; (b) to be regularly followed up at the outpatient clinic where the study was being conducted, receiving specific treatment for chronic leg ulcer for at least 3 months; (c) do not have severe communication deficits or cognitive and intellectual impairment that could hinder understanding or participation in the study; (d) voluntarily agree to participate in the study by signing the Informed Consent Form.

Considering the strong association between depression and poorer perception of QoL (especially in chronic diseases such as chronic leg ulcers) and the recommendation to combine the administration of the DLQI with assessment tools or scales that measure depression and anxiety symptoms, patients who had a high total score on the Quick Inventory of Depressive Symptomatology-Self Report - QIDS-SR16 (suggesting the presence of very severe depression) were excluded from the study. ${ }^{13,16-18}$ Individuals with depressive symptoms were evaluated by the department of psychology of the health care unit, and referred to specialized assessment if necessary.
Patients were approached individually in an appropriate environment by one of the principal investigators. They were asked to answer a brief clinical and sociodemographic survey, as well as two structured assessment instruments: DLQI and QIDSSR16. ${ }^{14,16}$ The variables investigated by the clinical and sociodemographic survey of the chronic leg ulcers are briefly shown in the table 1 .

The site of the lesions was defined according to the classification suggested by Callam et $a l_{1}{ }^{2}$ which divides the leg into three zones: Zone 1 is the foot, Zone 2 is the gaiter area (from 2,5 cm below the malleoli to the point at which the calf muscles became prominent posteriorly), and Zone 3 is the calf.

TABLE 1: Brief description of the variables included in the clinical and sociodemographic survey of patients with chronic leg ulcers. Bauru, 2012

\begin{tabular}{|c|c|}
\hline Gender & Categorical variable: Male; Female \\
\hline \multirow[t]{3}{*}{ Age } & Numeric variable $=$ year \\
\hline & Categorical variable $=$ Younger than 60 \\
\hline & years; 60 years or older \\
\hline \multirow[t]{2}{*}{ Ethnicity } & Categorical variable: White; Black; \\
\hline & Brown; Yellow; Indigenous \\
\hline Retired & Categorical variable: Yes; No; Sick pay \\
\hline \multirow[t]{3}{*}{ Functional capacity } & Categorical variable: Walking without \\
\hline & support; Walking with support; \\
\hline & Wheelchair user; Bedridden \\
\hline Weight, Height and & Numeric variables = kilograms $(\mathrm{kg})$; \\
\hline \multirow[t]{4}{*}{ Body Mass Index } & meters(m); BMI=weight $/$ height $^{2}$ \\
\hline & Categorical variable $=$ categories of body \\
\hline & mass index as recommended by the \\
\hline & World Health Organization ${ }^{34}$ \\
\hline \multirow[t]{4}{*}{ Probable etiology } & Categorical variable: Venous; \\
\hline & Arterial; Mixed; Neuropathic ulcers \\
\hline & related to Hansen's disease; Diabetic \\
\hline & neuropathy; Other \\
\hline \multirow[t]{2}{*}{ Number of lesions } & Categorical variable: One; Two; Three; \\
\hline & Four; Five or more \\
\hline Site of ulcer(s) ${ }^{*}$ & Zone 1, Zone 2, Zone 3 \\
\hline \multirow[t]{3}{*}{ Size $^{\dagger}$} & Categorical variable: $<4 \mathrm{~cm} 2$ \\
\hline & $-16 \mathrm{~cm} 2 ; 16,1-36 \mathrm{~cm} 2 ; 36,1-80 \mathrm{~cm} 2$; \\
\hline & $>80 \mathrm{~cm} 2$ \\
\hline Pain related to ulcer(s) & Dichotomous variable: Yes; No \\
\hline Odor or breakdown & Dichotomous variable: Yes; No \\
\hline \multicolumn{2}{|l|}{ related to ulcer(s) } \\
\hline Time of ulcer(s) onset & Numeric variable: Months \\
\hline
\end{tabular}

* Ulcer site according to the scheme proposed by Callan et al. ${ }^{2}$

$\dagger$ Larger diameter $\mathrm{x}$ smaller diameter for each lesion. 
The impact of chronic leg ulcers on QoL was assessed using the DLQI, which was developed in 1994 and is considered the first specific assessment instrument of QoL in dermatology. ${ }^{14,17,18}$ It consists of 10 questions divided into six domains. The answers are on a Likert scale. The DLQI has been validated and used to assess over 33 different skin conditions in at least 32 countries, and it is available in 55 languages. ${ }^{13}$ The total score ranges from zero to 30 . Higher values are correlated with greater impact on QoL. 13,14,17

To date, no studies have validated the use of the DLQI to assess the QoL of patients with chronic leg ulcers. However, this instrument has not been validated either for other skin conditions such as Hansen's disease, itching, and melanoma. ${ }^{13}$ Considering that the lack of validation of the DLQI for other skin conditions did not prevent excellent studies from being published in reputable journals, therefore greatly contributing to the understanding of the perception of QoL of patients with these skin conditions, we were led to choose this instrument rather than a generic assessment instrument of QoL. 13,14,17,18

The QIDS-SR16 was developed based on the diagnostic criteria of major depression provided by the DSM-IV. ${ }^{16}$ This self-administered instrument consists of 16 items. Its total score ranges between zero and 27 (the higher the score, the greater the severity of the depressive episode). The psychometric properties of the QIDS-SR16 have been tested extensively, ${ }_{1}^{16,19,20}$ and its scores have an excellent level of correlation with the scores of other well-established and more extensive instruments, such as the Hamilton Psychiatric Rating Scale for Depression (HRSD) and the Beck Depression Inventory (BDI). ${ }^{16}$

Data were recorded using the Microsoft Office Excel $^{\oplus}$. The analysis was performed using the SPSS ${ }^{\circledast}$ 15.0, including descriptive statistics for the sample profile, analysis of correlation between categorical variables, and parametric tests for and symetric continuous variables. The comparison between gender, age, and body mass index (BMI) was performed using the chi-square test. The internal consistency (reliability) of the DLQI in the sample was tested using Cronbach's alpha, considering that acceptable values were higher than 0.7. The relationship between the categories of the DLQI and QIDS-SR16 (ordinal categorical variables) were analyzed using the Mann-Whitney test, whereas Pearson's parametric test was used to evaluate the correlation between the total scores of the DLQI and QIDS-SR16, considering that significant $p$ values were $<0.05$.

Bivariate analysis was used with the purpose of establishing whether there were differences between the distributions of the DLQI and the variables age (age group), BMI (category), probable etiology, number of lesions, size, pain related to lesions, odor related to lesions, time since onset, and QIDS-SR16 category. We built a multiple regression model for categorical variables, using the DLQI as the dependent variable and the other variables as independent variables, including the $\mathrm{F}$ test for analysis, in order to assess which characteristics contribute to a significant change in the DLQI.

\section{RESULTS}

Forty-three patients were included in the study. Two patients were excluded because they had a score higher than 21 in the QIDS-SR16 (very severe depressive symptoms). Thus, we had a final sample of 41 individuals. $^{16}$

A descriptive analysis of sociodemographic and anthropometric variables of the sample is shown in table 2. The sample had a higher proportion of men and older adults, but there was no statistically significant difference between the groups according to age and gender $\left(X^{2}=0.092\right.$ and 0.286 , respectively). In terms of functional capacity, no bedridden patient was assessed during the study, and only one wheelchair user was included. The analysis of BMI showed higher prevalence of obesity $(43.9 \%)$, but there was no significant difference between the groups $\left(X^{2}=0.486\right)$, and no cases of malnutrition.

The clinical profile of the chronic leg ulcers is shown in table 3 . We found a higher prevalence of venous ulcers $(48.8 \%)$, with three patients showing traumatic ulcers and one hypertensive ulcer among the cases classified as "other causes". Twenty patients $(48.8 \%)$ had single ulcerated lesion, 16 patients (34.1\%) had two to three ulcers, and seven patients $(17.1 \%)$ had four or more ulcers. The median time of lesion onset was 48 months, with distribution of 12 months in the $25^{\text {th }}$ percentile, 48 months in the $50^{\text {th }}$ percentile, and 120 months in the $75^{\text {th }}$ percentile.

Table 4 shows the distribution of mean total scores on the DLQI and its domains, as well as the interpretation by category of impact on QoL. The evaluation of the perception of QoL according to the DLQI showed that $73.2 \%(n=30)$ of the sample believed that having chronic leg ulcers caused low or no impact on their QoL in the past week. There were no patients in the most severe impact category of the DLQI (total score between 21 and 30). Cronbach's alpha for the analysis of internal consistency of the DLQI, including its ten items, was 0.729, confirming the adequate reliability of the DLQI of our sample.

For $26.8 \%(n=11)$ of the sample, whose DLQI total score was higher than six (moderate or major impact on QoL), the most affected domains were Work and Study, with mean scores of 2.17 in the group of moderate impact and 3.0 in group of high impact, respectively.

Conversely, the domains showing the lowest 
TABLE 2: Characteristics of sociodemographic profile and anthropometric measures in a sample of patients with chronic leg ulcers. Bauru, 2012.

\begin{tabular}{|c|c|c|c|c|}
\hline Variable & & All $(\mathrm{N}=41)$ & Men $(n=24)$ & Women $(\mathrm{n}=17)$ \\
\hline Mean age (SD) & & 61.78 years $( \pm 12.37)$ & 59.63 years $( \pm 12.38)$ & 64.82 years $( \pm 12.06)$ \\
\hline \multirow[t]{2}{*}{ Age group } & Younger than 60 years & $16(39 \%)$ & $10(24.4 \%)$ & $6(14.6 \%)$ \\
\hline & 60 years or older & $25(61 \%)$ & $14(34.1 \%)$ & $11(26.8 \%)$ \\
\hline Ethnicity & & $29(70.7 \%)$ & $21(51.2 \%)$ & $8(19.5 \%)$ \\
\hline White & & $6(14.6 \%)$ & $1(2.4 \%)$ & $5(12.2 \%)$ \\
\hline Black & & $6(14.6 \%)$ & $2(4.9 \%)$ & $4(9.8 \%)$ \\
\hline \multicolumn{5}{|l|}{ Brown } \\
\hline Retired & & $30(73.2 \%)$ & $20(48.8 \%)$ & $10(24.4 \%)$ \\
\hline Yes & & $7(17.1 \%)$ & $2(4.9 \%)$ & $5(12.2 \%)$ \\
\hline No & & $4(9.8 \%)$ & $2(4.9 \%)$ & $2(4.9 \%)$ \\
\hline \multicolumn{5}{|l|}{ Sick pay } \\
\hline Functional Capacity & & $36(48.8 \%)$ & $20(48.8 \%)$ & $16(39 \%)$ \\
\hline Walking without support & & $4(9.8 \%)$ & $4(9.8 \%)$ & 0 \\
\hline Walking with support & & $1(2.4 \%)$ & 0 & $1(2.4 \%)$ \\
\hline \multicolumn{5}{|l|}{ Wheelchair user } \\
\hline Weight*, mean (SD) & & $81.02( \pm 17.38)$ & $81.96( \pm 19.70)$ & $79.70( \pm 13.95)$ \\
\hline Height†, mean (SD) & & $1.67( \pm 0.10)$ & $1.71( \pm 0.11)$ & $1.61( \pm 0.6)$ \\
\hline BMI‡, mean (SD) & & $28.80( \pm 5.59)$ & $27.68( \pm 5.14)$ & $30.37( \pm 5.97)$ \\
\hline Normal & & $11(26.8 \%)$ & $7(17.1 \%)$ & $4(9.8 \%)$ \\
\hline Overweight & & $12(29.3 \%)$ & $9(22 \%)$ & $3(7.3 \%)$ \\
\hline Obese & & $18(43.9 \%)$ & $8(19.5 \%)$ & $10(24.4 \%)$ \\
\hline
\end{tabular}

* Weight measured in kilograms $(\mathrm{kg})$

$\dagger$ Height measured in meters (m)

$\ddagger$ Body mass index measured statistically by dividing weight by squared height.

impact were: a) Leisure in the group with moderate impact on QoL (mean $=0.67)$; for comparison purpose, the high impact group had a score of 2.80 in this domain and the no impact group had a score of 0.10 , respectively, and b) Relations in the group of high impact on QoL, with a mean of 0:37.

The QIDS-SR16 showed a prevalence of $22 \%$ of severe depressive symptoms and $34.1 \%$ of mild depressive symptoms. Fifty percent $(n=7)$ of the patients with mild depressive symptoms reported that the chronic leg ulcers had no impact on their QoL in the past week according to the DLQI, whereas 50\% $(n=7)$ perceived chronic leg ulcers as causing small impact on their QoL. Conversely, those patients with severe depressive symptoms $(n=9)$ were distributed between major impact $(n=2)$, moderate impact $(n=2)$, and small impact $(n=5)$. The relationship between the total scores (Pearson, $\mathrm{p}=0.013$ ) and the categories of the DLQI and QIDS-SR16 (Mann-Whitney, p<0.001) was significant.

We analyzed the relationships between the DLQI and categorical variables using the bivariate analysis. There was significant correlation with age group $(p=0.010)$, presence of pain $(p=0.051)$, and odor $(p=0.050)$ related to ulcer, and the QIDS-SR16 $(p=0.001)$.

Table 5 shows the results of the multiple regression. This analysis evidenced which variables contributed to a significant change in the perception of QoL 
TABLE 3: Characteristics of sociodemographic profile and anthropometric measures in a sample of patients with chronic leg ulcers. Bauru, 2012.

\begin{tabular}{|c|c|c|c|}
\hline Variable & & $\mathrm{n}$ & $\%$ \\
\hline \multirow[t]{6}{*}{ Probable etiology } & Venous & 20 & 48.8 \\
\hline & Arterial & 1 & 2.4 \\
\hline & Mixed & 2 & 4.9 \\
\hline & Neuropathic ulcers related to Hansen's disease & 12 & 29.3 \\
\hline & Diabetic neuropathy & 2 & 4.9 \\
\hline & Other & 4 & 9.8 \\
\hline \multirow[t]{6}{*}{ Number of lesions } & One & 20 & 48.8 \\
\hline & Two & 11 & 26.8 \\
\hline & Three & 3 & 7.3 \\
\hline & Four & 3 & 7.3 \\
\hline & Five & 1 & 2.4 \\
\hline & More than five & 3 & 7.3 \\
\hline \multirow[t]{4}{*}{ Size } & Less than $4 \mathrm{~cm} 2$ & 31 & 58.5 \\
\hline & 4 to $16 \mathrm{~cm} 2$ & 18 & 33.9 \\
\hline & 16.1 to $36 \mathrm{~cm} 2$ & 3 & 5.6 \\
\hline & 36.1 to $80 \mathrm{~cm} 2$ & 1 & 1.8 \\
\hline \multirow[t]{6}{*}{ Site } & RLL* Zone 1 & 7 & 12.5 \\
\hline & RLL Zone 2 & 15 & 26.7 \\
\hline & RLL Zone 3 & 1 & 1.7 \\
\hline & LLL† Zona1 & 13 & 23.2 \\
\hline & LLL Zone 2 & 18 & 32.1 \\
\hline & LLL Zone 3 & 2 & 3.5 \\
\hline \multirow[t]{2}{*}{ Pain } & Yes & 21 & 51.2 \\
\hline & No & 20 & 48.8 \\
\hline \multirow[t]{2}{*}{ Odor } & Yes & 11 & 26.8 \\
\hline & No & 30 & 73.2 \\
\hline
\end{tabular}

Note: Because the variables "Probable etiology", "Size", and "Site" are characteristics of each one of the ulcers, their representations in the table may be larger than the number of patients in the sample $(n=41)$, since each patient may have more than one ulcer.

* Right Lower Limb

† Left Lower Limb

(DLQI). Although we could not infer causality using this type of test, it allowed us to identify which characteristics effectively contribute to the change in the study outcome, namely, the perception of QoL. We found that the etiology of the lesion $(\mathrm{p}<0.001)$, presence of pain related to the ulcer $(\mathrm{p}=0.001)$, time of onset $(\mathrm{p}=0.006)$, and severe depressive symptoms $(\mathrm{p}<0.001)$ are the variables most closely associated with changes in the DLQI.

\section{DISCUSSION}

The emergence of a wider understanding of the concept of QoL and its use in clinical practice and research have provided therapeutic approach closer to the patients' needs because it makes it easier to define which treatments and interventions are more beneficial or harmful. ${ }^{7}$ 
TABLE 4: Characteristics of perceived quality of life according to the Dermatology Life Quality Index (DLQI) and presence and severity of depressive symptoms according to the Quick Inventory of Depressive Symptomatology-Self Report (QIDSSR16) in the sample $(\mathrm{n}=41)$. Bauru, 2012.

\begin{tabular}{|c|c|c|}
\hline \multicolumn{3}{|l|}{ Variable } \\
\hline \multicolumn{3}{|l|}{ DLQI } \\
\hline \multicolumn{2}{|l|}{ Total score*, mean (SD) } & $4.46( \pm 3.97)$ \\
\hline \multicolumn{2}{|l|}{ Symptoms and Feelings ${ }^{\dagger}$} & $1.22( \pm 1.01)$ \\
\hline \multicolumn{2}{|l|}{ Activities of Daily Living $^{\dagger}$} & $0.80( \pm 0.87)$ \\
\hline \multicolumn{2}{|l|}{ Leisure $^{\dagger}$} & $0.85( \pm 1.10)$ \\
\hline \multicolumn{2}{|l|}{ Work and Study ${ }^{\ddagger}$} & $0.88( \pm 1.32)$ \\
\hline \multicolumn{2}{|l|}{ Treatment $^{\dagger}$} & $0.37( \pm 0.79)$ \\
\hline \multicolumn{2}{|c|}{ Interpretation of Total Score by Category } & n $(\%)$ \\
\hline \multicolumn{2}{|l|}{ No Impact } & $10(24.4 \%)$ \\
\hline \multicolumn{2}{|l|}{ Low Impact } & $20(48.8 \%)$ \\
\hline \multicolumn{2}{|l|}{ Moderate Impact } & $6(14.6 \%)$ \\
\hline \multicolumn{2}{|l|}{ High Impact } & $5(12.2 \%)$ \\
\hline \multicolumn{2}{|l|}{ QIDS-SR16 } & \multirow[t]{2}{*}{$11.85( \pm 3.56)$} \\
\hline \multicolumn{2}{|l|}{ Total score, mean $(\mathrm{SD}) \S$} & \\
\hline Severity of Depressive Symptoms & \multicolumn{2}{|r|}{$\mathbf{n}(\%)$} \\
\hline Light & \multicolumn{2}{|r|}{$14(34.1 \%)$} \\
\hline Moderate & \multicolumn{2}{|r|}{$18(43.9 \%)$} \\
\hline Severe & \multicolumn{2}{|r|}{$9(22 \%)$} \\
\hline \multicolumn{3}{|c|}{$\begin{array}{l}\text { * Score minimum of zero and maximum score of thirty. } \\
\dagger \text { Minimum score of zero and maximum score of six. } \\
\ddagger \text { Minimum score of zero and maximum score of three. } \\
\S \text { Minimum score of zero and maximum score of twenty-seven. }\end{array}$} \\
\hline $\begin{array}{l}\text { TABLE 5: Characteristics of percei } \\
\text { to the Dermatology Life Quality } \\
\text { and severity of depressive sympt } \\
\text { Inventory of Depressive Sympton } \\
\text { SR16) in the sample }(n=41) \text {. Baurt }\end{array}$ & $\begin{array}{l}\text { uality } \\
x \text { (DLQ } \\
\text { accordi } \\
\text { ogy-Sel } \\
2 \text {. }\end{array}$ & $\begin{array}{l}\text { I) life according } \\
\text { I) and presence } \\
\text { ng to the Quick } \\
\text { f Report (QIDS- }\end{array}$ \\
\hline & F & $\mathrm{p}$ \\
\hline Age & 2.859 & .103 \\
\hline Functional capacity & 1.533 & .227 \\
\hline $\mathrm{BMI}^{*}$ & .023 & .880 \\
\hline Probable etiology & 8.732 & .000 \\
\hline Number of lesions & .561 & .461 \\
\hline Size & .702 & .410 \\
\hline Pain related to ulcer & 14.232 & .001 \\
\hline Odor related to ulcer & 2.552 & .122 \\
\hline Time of onset & 8.867 & .006 \\
\hline QIDS-SR16 $^{\dagger}$ & 23.007 & .000 \\
\hline
\end{tabular}

\footnotetext{
* Body Mass Index

† Quick Inventory of Depressive Symptomatology-Self Report
}

When a dermatologist acknowledges the impact of a skin condition on a patient's QoL, this physician may feel the need to introduce a systemic or adjuvant therapy, or to refer the patient to inpatient care or outpatient treatment and psychological follow-up. . $1,22^{2}$

The sociodemographic characteristics of the sample showed a higher proportion of older adults $(61 \%)$ and men $(58.53 \%)$. The mean age of the female group was slightly higher than the male group (64.82 years versus 59.63 years); however, there was no significant difference between the groups. Except for a case series study conducted in South Africa demonstrating two prevalence peaks between 30-39 years and 50-69 years, previous studies confirms the finding of high mean ages, close to 75 years, in some population surveys. $^{23,5,5,623}$ Authors who have shown higher prevalence in women have also found higher mean ages in their samples. Therefore, such studies unanimously suggest the association between chronic leg ulcers and old age. . $^{3,5}, 6$

Moffati et al. found impaired functional capacity in $64 \%$ of 113 patients with chronic leg ulcers living in London. ${ }^{5}$ Of these, $37 \%$ were wheelchair users, bedridden, or could walk only at home or a long-term care facility using an assistive device (canes or walkers); the remaining $27 \%$ were able to walk with the help of an assistive device even outside their homes. Only 11.2\% of our study sample had any mobility deficits. However, when compared with the population of the study by Moffati et al., our sample had a lower mean age. This might be one of the causes of the difference between the profiles of mobility of these two samples. ${ }^{5}$ Unfortunately, other characteristics that could explain the correlation between mobility and chronic leg ulcers (such as, size of lesions, number of lesions, and pain) were not analyzed in the study by Moffati et al. ${ }^{5}$

The mean BMI in our sample was $28.80 \mathrm{~kg} / \mathrm{m}^{2}$. Women had slightly higher BMI (30.37 versus 27.68 ). Patients with chronic leg ulcers had a higher frequency of obesity (43.9\%) and overweight $(29.3 \%)$ when compared with patients with normal BMI (26.8\%). Although they did not measure weight and height, Frade et al found that obesity was a comorbidity in $20.2 \%$ of the patients with chronic leg ulcers investigated in Juiz de Fora, Minas Gerais, Brazil. ${ }^{24}$ In a study evaluating only patients with diabetic foot ulcers, Yekta et al found prevalence of overweight in $63.3 \%$ of their sample. ${ }^{25}$

The probable etiology most frequently mentioned in our study was venous $(48.8 \%)$ followed by neuropathy in leprosy $(29.3 \%)$. To date, no consensus has been reached in the literature regarding the classification of the causes of chronic leg ulcers, limiting the comparison between different studies. Nevertheless, 
most authors found predominance of venous ulcers in their surveys. ${ }^{23,5}$ The high frequency of neuropathic ulcers related to Hansen's disease in our study was expected and it is associated with the profile of the study participants, who were being treated at a reference center for the treatment of individuals with Hansen's disease and/or sequelae of this condition. In the population investigated by Callam et al, the venous causes were the most prevalent, followed by arterial etiologies and ulcers associated with rheumatoid arthritis. Moffati et al found venous etiology in $43 \%$ of cases, followed by multifactorial causes in 35\% of patients. ${ }^{2,5}$

A systematic review published by Herber et al. points out that pain, assessed using quantitative and qualitative analysis, is the worst experience described by patients with chronic leg ulcers. Pain is also the most common complaint among men..$^{15}$ The same authors reviewed publications about the analysis of odor related to chronic leg ulcers and found a prevalence of $24 \%$ of odor associated with negative effect on the patients' social life and lower levels of satisfaction with life, as well as higher depression scores..$^{15}$ In the present analysis, we found a prevalence of pain associated with chronic leg ulcers in $51.2 \%$ of the sample, and odor related to ulcers in $26.8 \%$ of cases.

Our patients had a median time of onset of their chronic leg ulcers of 48 months. Moffati et al investigated British patients and found a median of 8 months of time of onset, whereas Baker et al found a mean duration of 26 weeks in Australian patients assessed in a hospital., We found a high frequency $(48.8 \%)$ of single ulcers, and few patients had four or more ulcers (17.1\%).

The mean total score on the DLQI was 4.46 (possible range: $0-30$ ). As it is shown in table 4, there was a greater distribution of patients between the groups showing no impact (0-1) and low impact (2-5) on the QoL, including 73.2\% of the sample; whereas the groups with moderate impact (6-10) and high impact (11-20) accounted for $26.8 \%$ of the sample. At first glance, finding a low mean total score on the DLQI may convey the impression that the condition does not have an impact on the patients' QoL.

Tejada et al. evaluated 548 patients in southern Brazil and found only two cases of ulcers and/or factitious dermatitis (not specified as leg ulcers) showing a median of 9 on the DLQI. ${ }^{7}$ In the same population, the authors showed medians of 3 on the DLQI for basal cell carcinoma and squamous cell carcinoma, whereas the scores were higher than 12 for atopic dermatitis and higher than 15 for psoriasis. ${ }^{7}$ Nevertheless, the authors did not provide descriptions of the number of lesions or clinical severity of the skin conditions. They also did not analyze the presence of depressive symptoms in the sample. Hongbo et al. suggested that a total score higher than 10 on the DLQI should provide strong evidence of the need for active intervention and support to treat the patient's skin condition. ${ }^{21}$

When using the DLQI, it is possible to obtain specific information on the impact of the skin condition on different domains and aspects of a person's life. While evaluating the mean values of the whole sample, we found higher impacts on the domains Symptoms and Feelings (1.22, range 0-6) and Work and Study (0.88, range 0-3). When we evaluated the means of the DLQI domains according to the meanings of its total scores (degrees of impact), the domain Work and Study had the highest impact, with means higher than 2.1 between the moderate and high impact groups. A systematic review of the literature conducted by Herber et al confirmed the negative impact of leg ulcers on occupational domains, leisure activities, social isolation, and psychological domains. ${ }^{15}$

Jull et al. investigated the perception of QoL in patients with chronic leg ulcers using a generic instrument to measure QoL, the Short Form 36 Question Health Survey (SF-36). ${ }^{26}$ This instrument was used to measure the perceptions found in other chronic conditions, such as arthritis and diabetes, and the results were similar between these diseases. In Germany, Herberger et al. used a specific instrument, called the Freiburg Life Quality Assessment of Wounds, which has not been validated in Portuguese. ${ }^{27}$ Similarly, Gonzalez-Consuegra and Verdú showed the process of cultural adaptation into Spanish of another QoL instrument for chronic leg ulcers, the Charing Cross Venous Ulcer Questionnaire, which is not available in Portuguese. ${ }^{28}$ A systematic review of the literature on the impact of leg ulcers on QoL found a large proportion of qualitative and quantitative studies using the SF-36 and the Nottingham Health Profile. ${ }^{15}$

Although the use of the DLQI to assess QoL in patients with chronic leg ulcers has not been reported in the literature, evidence indicates that this instrument has been the most commonly used method to assess QoL, which explains its use in the present study. $13,21,29,30$ Thus, the possibility of increasing the practical use of the instrument is enriching. Therefore, there is need for further studies aimed at validating and analyzing the psychometric properties of the DLQI in patients with chronic leg ulcers.

We found evidence of association between worse perception of QoL and depressive symptoms. The recommendation of combining the administration of the DLQI with a brief screening for emotional components led us to use the QIDS-SR16 and to analyze the correlation between the variables, which was significant in both tests (Pearson, $p=0.013$ ) when we analyzed the correlation between the total scores on the DLQI 
and QIDS-SR16 and the ordinal categories of the instruments (Mann-Whitney, $\mathrm{p}<0.001$ ). ${ }^{13,31-33}$

When we used the multiple regression analysis, adopting the DLQI as the dependent variable, we found that probable etiology of the lesion, presence of pain related to the lesion, time of onset, and severity of the depressive symptoms were the variables that had an influence on the DLQI (Table 5). In a multivariate analysis involving outpatients with various skin conditions, Tejada et al found that age, marital status, educational level, and number of concomitant skin diseases also had an influence on the DLQI.

Some limitations to the interpretation of our results should be considered. These limitations are mainly related to the small number of patients and the type of population included in the analysis, which explains, for example, the unusual finding of a high proportion of neuropathic ulcers related to Hansen's disease in our sample. Some specific characteristics of these ulcerations might have changed the pattern of variables, such as perception of pain associated with the ulcer. Similarly, it is important to note that the instrument used to assess the perception of QoL in this sample of patients with leg ulcers still lacks validation for this condition. However, the absence of validation did not prevent this instrument from being used in similar studies about other skin conditions. ${ }^{7,10,34-36}$

Despite these limitations, the present study provides some important contributions. Few studies have conducted such a deep investigation of the clinical and epidemiological profile of chronic leg ulcers in outpatients. Similarly, identifying the variables with the highest influence on the DLQI of patients with chronic leg ulcers is important so that studies with more complex designs and better evidence can be planned, thus making it possible to analyze the causal relationship of these characteristics.

Chronic leg ulcers, as well as other skin conditions, may not represent a high risk of death, but they are often chronic and difficult to treat, significantly impairing the QoL of patients.

According to Kini and DeLong, if a dermatologist is able to identify which aspect of the disease has the most significant impact on the health-related QoL aspects of his/her patient (symptom versus emotional domain versus functional impact), then the therapeutic interventions may be adapted to fulfill the patient's needs, not only the physician's intentions. ${ }^{33}$ It may be necessary to go through a new period of adjustment, both in terms of the use of the QoL instruments by health care professionals and the instruments themselves regarding their psychometric properties.

\section{CONCLUSION}

In a sample of 41 patients with chronic leg ulcers, whose mean age was 61.78 years, we found a high proportion of functional independence, prevalence of venous ulcers in agreement with the rates reported in the international literature, and unusual proportion of neuropathic ulcers related to Hansen's disease. When DLQI was applied we found that $73.2 \%$ of participants perceived low or no impact of chronic leg ulcers on their QoL in the past week, and 26.8\% perceived moderate or high impact of the skin condition during the same period.

According to the multiple regression analysis, the variables that had an influence on the DLQI were: lesion etiology, pain related to the ulcer, time of onset, and severity of depressive symptoms. The identification of these variables warrants the need for developing studies to confirm whether there is a causal relationship between these characteristics and the QoL of patients with chronic leg ulcers. The present study also provides support for future validation of this assessment instrument regarding this skin condition. 


\section{REFERENCES}

1. Abbade LPF. Diagnósticos diferenciais de úlceras crônicas dos membros inferiores. In: Malagutti W, Kakihara CT, editors. Curativos, Estomias e Dermatologia: Uma abordagem multiprofissional. São Paulo: Martinari; 2010. p. 77-93.

2. Callam MJ, Harper DR, Dale JJ, Ruckley CV. Chronic ulcer of the leg: clinical history. Br Med J (Clin Res Ed). 1987;294:1389-91.

3. Baker SR, Stacey MC, Jopp-McKay AG, Hoskin SE, Thompson PJ. Epidemiology of chronic venous ulcers. Br J Surg. 1991;78:864-7.

4. Barclay KM, Granby T, Elton PJ. The prevalence of leg ulcers in hospitals. Hosp Med 1998;59:850.

5. Moffatt CJ, Franks PJ, Doherty DC, Martin R, Blewett R, Ross F. Prevalence of leg ulceration in a London population. QJM. 2004;97:431-7.

6. Callam MJ, Ruckley CV, Harper DR, Dale JJ. Chronic ulceration of the leg: extent of the problem and provision of care. Br Med J (Clin Res Ed). 1985;290:1855-6.

7. Tejada CS, Mendoza-Sassi RA, Almeida HL Jr, Figueiredo PN, Tejada VF. Impact onthe quality of life of dermatological patients in southern Brazil. An Bras Dermatol.2011;86:1113-21.

8. Patrick DL. A qualidade de vida pode ser medida? Como?. In: Fleck MPA, editor. A avaliação de qualidade de vida: Guia para profissionais da saúde. Porto Alegre: ArtMed; 2009. p. 29-39.

9. Barbato MT, Bakos L, Bakos RM, Prieb R, Andrade CD. Predictors of quality of life in patients with skin melanoma at the dermatology department of the Porto Alegre Teaching Hospital. An Bras Dermatol. 2011;86:249-56.

10. Bottene IMC, Reis VMS. Quality of life of patients with paucibacillary leprosy. An Bras Dermatol. 2012;87:408-11.

11. Ludwig MWB, Oliveira MS, Muller MC, Moraes JFD. Quality of life and site of the lesion in dermatological patients. An Bras Dermatol. 2009;84:143-50.

12. Ue AP, Souza PK, Rotta O, Furlani Wde J, Lima AR, Sabbag DS. Quality of life assessment in patients with chronic urticaria. An Bras Dermatol. 2011;86:879-904.

13. Basra MK, Fenech R, Gatt RM, Salek MS, Finlay AY. The Dermatology Life Quality Index 1994-2007: a comprehensive review of validation data and clinical results. $\mathrm{Br} J$ Dermatol. 2008;159:997-1035

14. Finlay AY, Khan GK. Dermatology Life Quality Index (DLQI)--a simple practical measure for routine clinical use. Clin Exp Dermatol. 1994;19:210-6.

15. Herber OR, Schnepp W, Rieger MA. A systematic review on the impact of leg ulceration on patients' quality of life. Health Qual Life Outcomes. 2007;5:44.

16. Rush AJ, Trivedi MH, Ibrahim HM, Carmody TJ, Arnow B, Klein DN, et al. The 16-Item Quick Inventory of Depressive Symptomatology (QIDS), clinician rating (QIDS-C), and self-report (QIDS-SR): a psychometric evaluation in patients with chronic major depression. Biol Psychiatry. 2003;54:573-83.

17. Finlay AY. Quality of life assessments in dermatology. Semin Cutan Med Surg. 1998;17:291-6.

18. Finlay AY. Skin disease disability: measuring its magnitude. Keio J Med. 1998;47:131-4

19. Bernstein IH, Rush AJ, Stegman D, Macleod L, Witte B, Trivedi MH. A Comparison of the QIDS-C16, QIDS-SR16, and the MADRS in an Adult Outpatient Clinical Sample. CNS Spectr. 2010;15:458-68.

20. Lamoureux BE, Linardatos E, Fresco DM, Bartko D, Logue E, Milo L. Using the QIDSSR16 to identify major depressive disorder in primary care medical patients. Behav Ther. 2010;41:423-31.

21. Hongbo $\mathrm{Y}$, Thomas $\mathrm{CL}$, Harrison MA, Salek MS, Finlay AY. Translating the science of quality of life into practice: What do dermatology life quality index scores mean? J Invest Dermatol. 2005;125:659-64

22. David SE, Ahmed Z, Salek MS, Finlay AY. Does enough quality of life-related discussion occur during dermatology outpatient consultations? Br J Dermatol. 2005;153:9971000.

23. Rahman GA, Adigun IA, Fadeyi A. Epidemiology, etiology, and treatment of chronic leg ulcer: experience with sixty patients. Ann Afr Med. 2010;9:1-4.
24. Frade MAC, Cursi IB, Andrade FF, Soares SC, Ribeiro WS, Santos SV, et al. Leg ulcer: an observational study in Juiz de Fora, MG (Brazil) and region. An Bras Dermatol. 2005;80:41-6.

25. Yekta Z, Pourali R, Ghasemi-Rad M. Comparison of demographic and clinical characteristics influencing health-related quality of life in patients with diabetic foot ulcers and those without foot ulcers. Diabetes Metab Syndr Obes. 2011;4:393-9.

26. Jull A, Parag V, Walker N, Rodgers A. Responsiveness of generic and disease-specific health-related quality of life instruments to venous ulcer healing. Wound Repair Regen. 2010;18:26-30.

27. Herberger K, Rustenbach SJ, Grams L, Münter KC, Schäfer E, Augustin M. Quality-ofcare for leg ulcers in the metropolitan area of Hamburg - a community-based study. $J$ Eur Acad Dermatol Venereol. 2012;26:495-502.

28. González-Consuegra RV, Verdú J. Proceso de adaptación al castellano del Charing Cross Venous Ulcer Questionnaire (CCVUQ) para medir la calidad de vida relacionada con la salud en pacientes con úlceras venosas. Gerokomos. 2010;21:80-7.

29. Basra MK, Chowdhury MM, Smith EV, Freemantle N, Piguet V. A Review of the Use of the Dermatology Life Quality Index as a Criterion in Clinical Guidelines and Health Technology Assessments in Psoriasis and Chronic Hand Eczema. Dermatol Clin. 2012;30:237-44, viii.

30. Finlay AY, Basra MK, Piguet V, Salek MS. Dermatology Life Quality Index (DLQI): A Paradigm Shift to Patient-Centered Outcomes. J Invest Dermatol. 2012;132:2464-5.

31. Cruz LN, Fleck MP, Polanczyk CA. Depression as a determinant of quality of life in patients with chronic disease: data from Brazil. Soc Psychiatry Psychiatr Epidemiol. 2010;45:953-61

32. Rocha NS, Fleck MP. Evaluation of quality of life in adults with chronic health conditions: the role of depressive symptoms. Rev Bras Psiquiatr. 2010;32:119-24.

33. Kini SP, DeLong LK.. Overview of health status quality-of-life measures. Dermatol Clin. 2012;30:209-21, xiii.

34. Proto RS, Machado Filho CD, Rehder JR, Paixão MP, Angelucci RI. Quality of life in leprosy: a comparative analysis between patients in the Amazon region and patients in Santo André in the ABC region of São Paulo, Brazil. An Bras Dermatol. 2010;85:939-41.

35. Martins BDL, Torres FN, Oliveira MLW-D-R de. Impact on the quality of life of patients with Hansens disease: correlation between Dermatology Life Quality Index and disease status. An Bras Dermatol. 2008;83:39-43.

36. Budel AR, Raymundo AR, Costa CF, Gerhardt C, Pedri LE. Profile of patients affected by Hansen's disease seen at the Outpatient Clinic of Dermatology at Hospital Evangélico de Curitiba. An Bras Dermatol. 2011:86:942-6.

MAILING ADDRESS:
Patrick Alexander Wachholz
Rodovia Comandante João Ribeiro de Barros, Km 225/226
Distrito Industrial (Aimorés)
17034-971 - Bauru - SP
Brazil
E-mail: P_wachholz@hotmail.com

How to cite this article: Wachholz PA, Masuda PY, Nascimento DC, Taira CMH, Cleto NG. Quality of life profile and correlated factors in patients with chronic leg ulcers from the center-west of the São Paulo State, Brazil. An Bras Dermatol. 2014;89(1):73-81. 